Final version:

Ghisi, F.A., da Silveira, J.A.G., Kristensen, T., Hingley, M.K., and Lindgreen, A. (2008), "Horizontal alliances amongst small retailers in Brazil", British Food Journal, Vol. 110, No. 4/5, pp. 514-538. (ISSN 0007-070X)

For full article, please contact LindgreenA@cardiff.ac.uk

\title{
Horizontal Alliances Amongst Small Retailers in Brazil
}

Flávia A. Ghisi and José A. G. da Silveira, Universidade de São Paulo

Tore Kristensen, Copenhagen Business School

Martin Hingley, Harper Adams University College ${ }^{1,2}$

Adam Lindgreen, Hull University Business School

\footnotetext{
${ }^{1}$ For all correspondence, please contact dr. Martin Hingley, School of Management, Harper Adams University College, Newport, Shropshire, TF10 8NB, the UK. Email: mhingley@ harper-adams.ac.uk. Telephone $+44(0)$ 1952815386.

${ }^{2}$ The authors contributed equally
} 


\section{Horizontal Alliances Amongst Small Retailers in Brazil}

\section{Research paper}

Purpose - Application of the horizontal alliance paradigm has particularly relevance to small retailers. It is a powerful mechanism for independents and non-integrated chain retailers to develop competitive advantage, maintaining and improving their performance. This article analyses the theory of alliance in the context of the retail sector.

Design/methodology/approach - To reach our objective, both quantitative and qualitative research was carried out with horizontal retail alliances in Brazil.

Findings - Focusing on the alliances among independents and non-integrated chain retailers, our discussion covers specifically the following issues: the reasons for forming a strategic alliance in retail; minimum criteria for the alliance activity amongst retailers; steps that managers must take to create a competitive retail alliance; critical core competencies to be developed on the retail alliance; types of retail alliances; and, finally, forms of strategic retail alliances and stages / steps to develop a retail alliance over time.

Research limitations - The study considers horizontal alliances in a Brazilian retail context, which is in some ways unique, however, key principles and findings are very much transferable.

Practical implications - The study is of value not only to researchers of retail horizontal alliances, but offers retail practitioners specific experience and guidance. 
Originality/value of the paper - It was identified from the literature that there have been relatively few theoretical and practical studies available that analyse the relationship between the outlined themes concerned with alliances and small retailers. The discussion in our paper provides useful information and new insights to both academics and practitioners.

Keywords - Horizontal alliance; retail sector; small retailers; Brazil. 


\section{Introduction}

Over the past decades, the retail industry in many countries has experienced a growing rate of concentration, resulting in big chains capturing a large portion of the market that was previously represented by small stores. As a consequence, for many years the expansion of national chains and the future of independent and non-integrated chain retailers have attracted policy attention and been regarded as a matter of some concern by practitioners, academics, industry commentators, and government agencies (Byrom, Medway, and Warnaby, 2003; D'Andrea, Lopez-Aleman, and Stengel, 2006; Dawson and Kirby, 1979; Dobson, 2002; Frazier and Niehm, 2004; Ghisi, Martinelli, and Kristensen, 2006; Megicks, 2001; Smith and Sparks, 2000).

In Brazil, the focus of this study, large chains have intensified their domination of the market through acquisitions as a strategy for growth, trying to enlarge their business in neighbourhood areas, as well as opening new, smaller stores. The Brazilian supermarket sector also became much more attractive to international chains in the 1990 s due to the stability of the country's economy. The sector attracted particular interest from the American, Dutch, Portuguese, and French chains who have gained market share in the recent years in the country (Ghisi, Martinelli, and Kristensen, 2006).

The growth of mergers and acquisitions in Brazil resulted in a competitive advantage to big retailers and in consequence, the only alternative for small businesses would be to sell their companies and leave the market (Farina, Nunes, and Monteiro, 2005). With the advent of the new international chains, independents and non-integrated chain retailers disappeared from the Brazilian market, as it became difficult for these companies to compete with major 
retailers that can easily offer lower prices (Ghisi, Martinelli, and Kristensen, 2006). To reverse this situation, small retailers had few alternatives: better understanding consumer's needs and alliances' activities and to provide professionalism of management.

In recent decades, the importance of alliances activities to small firms has attracted considerable interest (Barnir and Smith, 2002; Chung, Luo and Wagner, 2006; Donckels and Lambrecht, 1995; Jarratt, 1998; Hoffmann and Schosser, 2001). Also, the domination of large retail chains and the challenges faced by small retailers have received attention (Baron et al., 2001; Bell; Coca-Stefaniack et al., 2004; Dobson, 2002; McGee and Rubach, 1996/1997; Smith and Sparks, 2000). Previous studies concerned the alliances in the retail sector (Bailey, Clarke-Hill, and Robinson, 1995; Clarke-Hill, Robinson, and Bailey, 1998; Stoel, 2002; Wingate, 1941). However, a literature review reveals that despite the relevance and proliferation of the retail alliances, and the growing concern about the survival of the independent and non-integrated chain retailers in the market, few empirical studies investigate the theme (Elg and Johansson, 1996; Frazier and Niehm, 2004; Ghisi, Martinelli, and Kristensen, 2006; Masurel and Janszen, 1998; Shaw, Dawson, and Harris, 1994).

This study strives to fill this gap in the literature. The article discusses the theory of horizontal alliances in the retail sector, and new insights for both academic and practitioners. Focusing on the alliances among independent and non-integrated chain retailers, the article discusses specifically the following aspects: reasons for forming a strategic alliance; minimum criteria for alliance activity among retailers; steps that managers must take to create a competitive alliance; critical core competencies to be developed in the retail alliance; types of retail alliances; and, finally, forms of strategic retail alliances and stages / steps in developing a retail alliance over time. 


\section{Alliance Theory in the Business Field}

Previous researches have dealt with specific issues about alliances in the business field, such as the reasons for their formation (Hipkin and Naudé, 2006; Murray and Mahon, 1993; Oliver, 1990); vertical alliances (Collins and Burt, 2003; Murdock, 2002; Quintana-Garcia and Bernavides-Velasco, 2005; Ruíz, 2000; Schmitz, Frankel, and Frayer, 1995) and international, global, and cross-border alliances (2001; Kauser and Shaw, 2004; Kumar and Nti; 2004; Robinson and Clarke-Hill, 1995).

Some academics consider the purpose of alliance (with respect to strategic or operational focus) in terms of contribution to the achievement of a future competitive position, or enhanced operational efficiency (Clarke-Hill, Robinson, and Bailey, 1998; Jarratt, 1998; Sheth and Parvatiyar, 1995). Others argue that the alliance can be defensive (instinct to survive) or offensive (to achieve competitive advantage) (Murray and Mahon, 1993). However, the delineation between these two concepts is not always clear, as in the same alliance some partners can decide to join for gains in business effectiveness and others to maintain their business; thus making it difficult to define a singular purpose.

Alliances as a strategic concept have received wide interest in the literature, particularly concerning the growth in popularity of alliances between competitors (Clarke-Hill, Robinson, and Bailey, 1998). A strategic alliance is different from other collaborative arrangements because it occurs in the context of a company's long-term plans, and also it aims to improve the participants' competitive standing in either domestic or international markets. 
Considering the horizontal alliance, the existence of limited empirical studies has been pointed out (Bengtsson and Kock, 1999; Ensign, 1998; O'Donnell et al., 2001; Rindfleisch, 2000); however, both are equally important. One argument for the focus on vertical alliances is the fact that economic benefits along the entire supply chain are more perceptible, as in horizontal alliances the earnings are more informal and invisible (social benefits); and relationships are built mainly on information and social exchanges (Bengtsson and Kock, 1999; O'Donnell et al., 2001).

Very few studies have explicitly treated the problems and task of managing a portfolio of many different alliances (Hoffmann, 2005). Little is written concerning the development process of the interorganisational relationships (Doz, 1996; O’Donnell et al., 2001; Ring and Van de Ven, 1994). Also, too little attention is given to the alliance manager as a central figure in determining the success / failure of an alliance (Spekman et al., 1998). Doz (1996) discusses the lack of research spanning individual behaviours and the organisational processes, as well as the fact that few studies have examined how organisations adjust their level, mode, and commitment to cooperation over time. Few authors have examined alliances in the context of small and medium-sized enterprises from a regional business perspective (Donckels and Lambrecht, 1995; Jarrat, 1998); and only a few researches have been conducted about the factors influencing small firm performance (Frazier and Niehm, 2004).

In reviewing the existing research of alliances in the business field and trying to address some of these gaps, the following issues of interest to this study have been identified (in Table 1). 
Table 1. Relevant issues selected about the alliances between partners

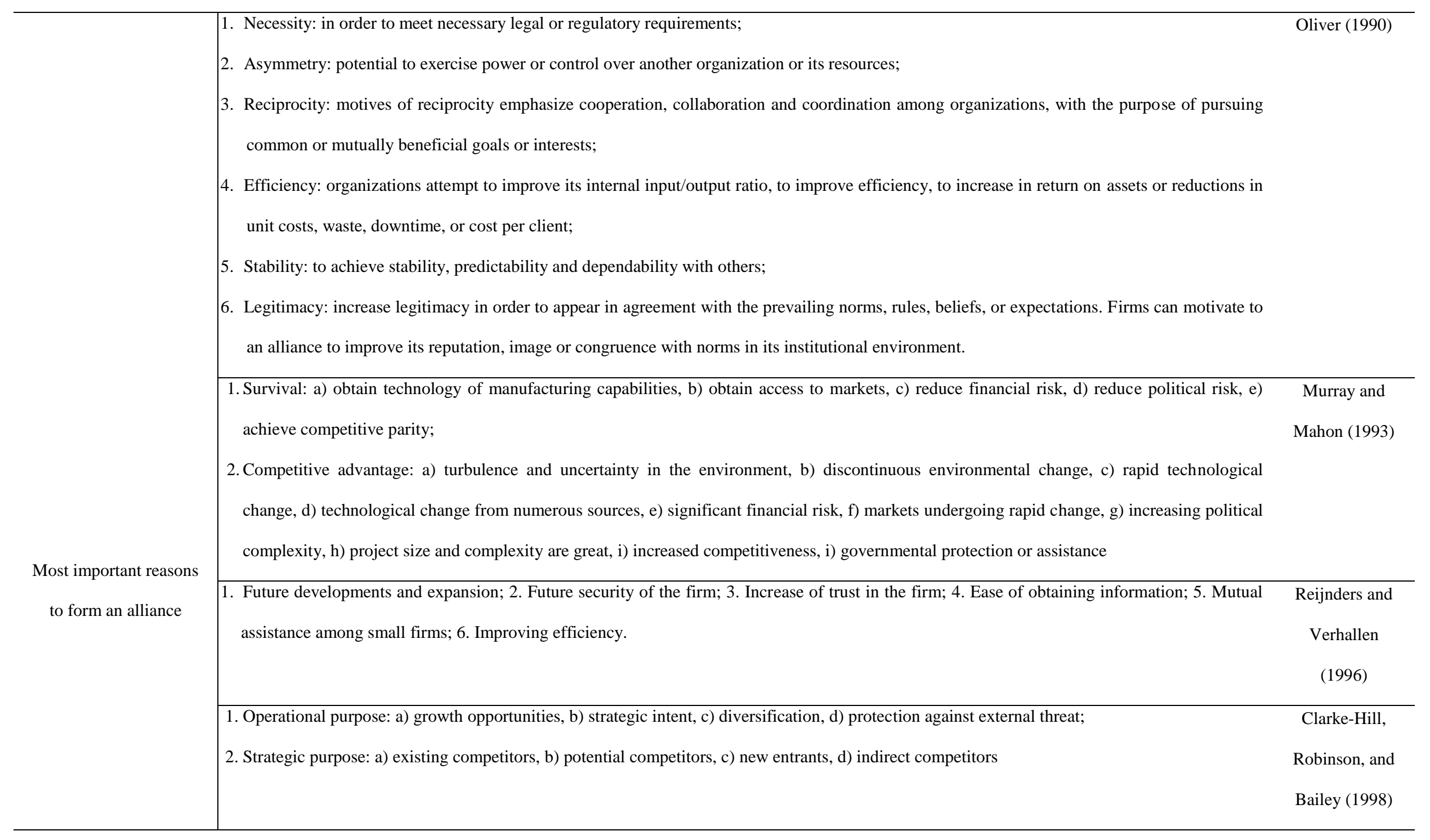




\begin{tabular}{|c|c|c|}
\hline & $\begin{array}{l}\text { 1. To produce technology fusion; 2. Market-related reasons: going around entry barriers, to pool resources, increase efficiency, share expertise, } \\
\text { reduce cost, increase market share, become more competitive, reduce/share risk, gain access to new market segments and sourcing raw materials }\end{array}$ & $\begin{array}{l}\text { Vyas, Shelburn, } \\
\text { and Rogers } \\
\text { (1995) }\end{array}$ \\
\hline & $\begin{array}{l}\text { 1. Growth strategies and entering new markets; } 2 \text {. Obtain new technology and/or best quality of cheapest cost; } 3 \text {. Reduce financial risk and share } \\
\text { costs of research and development; } 4 \text {. Achieve or ensure competitive advantage }\end{array}$ & $\begin{array}{l}\text { Elmuti and } \\
\text { Kathawala } \\
\text { (2001) }\end{array}$ \\
\hline $\begin{array}{l}\text { Minimum criteria for the } \\
\text { alliance activity exist }\end{array}$ & $\begin{array}{l}\text { 1.Existence of strategically significant goals; } 2 \text {. Mutual (but not necessarily equal) benefits; } 3 \text {. The benefits to be achieved outweigh those derived } \\
\text { from other means/actions }\end{array}$ & $\begin{array}{c}\text { Murray and } \\
\text { Mahon (1993) }\end{array}$ \\
\hline \multirow{2}{*}{$\begin{array}{l}\text { Steps that managers must } \\
\text { take to create a } \\
\text { competitive alliance }\end{array}$} & $\begin{array}{l}\text { 1. Understand the firm's core competence and skill; 2. Choose partners with complementary skills and markets; } 3 \text {. Match external alliances with } \\
\text { internal strategic; } 4 \text {. Keep alliance personnel long-term; } 5 \text {. Work informally with other company before entering a formal alliance; } 6 \text {. Measuring } \\
\text { the alliance's worth }\end{array}$ & Lei (1993) \\
\hline & $\begin{array}{l}\text { 1. Anticipation of business risks from the alliance } \\
\text { 2. Careful examination of alliance business plan for analytical soundness } \\
\text { 3. Realistic alliance feasibility study } \\
\text { 4. Linkage of budgets to resources and strategic priorities } \\
\text { 5. Knowledge of partner's alliance experiences } \\
\text { 6. Rigorous resource planning } \\
\text { 7. Coupling pay and investment with performance }\end{array}$ & $\begin{array}{c}\text { Pekar and Allio } \\
\text { (1994) }\end{array}$ \\
\hline
\end{tabular}




\begin{tabular}{|c|c|c|}
\hline Critical core & 1. The idea: create a vision in which partners play a critical role & Lorenzoni and \\
\hline competencies to be & 2. The investment: develop a strong brand image and effective systems and support & Baden-Fuller \\
\hline developed in an & 3. The climate: create an atmosphere of trust and reciprocity & $(1995)$ \\
\hline alliance & 4. The partners: develop mechanisms for attracting and selecting partners & \\
\hline Types of alliances & $\begin{array}{l}\text { 1.Y-alliances: local or national alliances formed to compensate for structural competitive disadvantages in relation to chain store companies through } \\
\text { consolidation degression and competence-enhancing effects. Focused specially in buying actions, but expanding to other join activities } \\
\text { 2.X-alliances: cross-border extension of the operative alliance, which is consolidated on a supranational level, triggered by the growing influence of the } \\
\text { globalisation, with the objective of achieving significant improvements in both efficiency and effectiveness. The strategic resources of the partners must have } \\
\text { a complementary structure, which needs to be optimised. }\end{array}$ & $\begin{array}{c}\text { Zentes and } \\
\text { Swoboda (2000) }\end{array}$ \\
\hline $\begin{array}{l}\text { Forms of strategic } \\
\text { alliances }\end{array}$ & $\begin{array}{l}\text { Joint marketing/promotion (54\%); Joint selling or distribution (42\%); Production (26\%); Design collaboration (23\%); Technology licensing (22\%); Research } \\
\text { and development contracts (19\%); Other outsourcing purposes (19\%). }\end{array}$ & $\begin{array}{c}\text { Elmuti and } \\
\text { Kathawala } \\
\text { (2001) }\end{array}$ \\
\hline \multirow[t]{2}{*}{$\begin{array}{l}\text { Steps to create an } \\
\text { consolidated } \\
\text { alliance evolution }\end{array}$} & $\begin{array}{l}\text { 1. Partner selection: select most appropriate partners; understand how each partner's objectives and strategies are likely to change over time } \\
\text { 2. Planning/Negotiation: communicate the alliance's shared goals with all key middle managers and technical staff to discuss ways to develop a win-win } \\
\text { relationship; negotiate goals and objectives of the relationship and deal with the uncertainties and the complexities of day-to-day activities that cannot be pre- } \\
\text { specified in a legal document } \\
\text { 3. Implementation/Control: develop protocols that enable firms to learn from one another, while simultaneously protecting their core skills and proprietary } \\
\text { technologies from knowledge leaks and potential partner encroachment; use of different types of performance evaluation criteria }\end{array}$ & $\begin{array}{l}\text { Lei, Slocum, } \\
\text { and Pitts (1997) }\end{array}$ \\
\hline & $\begin{array}{l}\text { 1. Strategic analysis and decision to co-operate; 2. Search for a partner; 3. Designing the partnership; 4. Implementation and management of the partnership; } \\
\text { 5. Termination of the partnership }\end{array}$ & $\begin{array}{l}\text { Hoffmann and } \\
\text { Schlosser (2001) }\end{array}$ \\
\hline
\end{tabular}




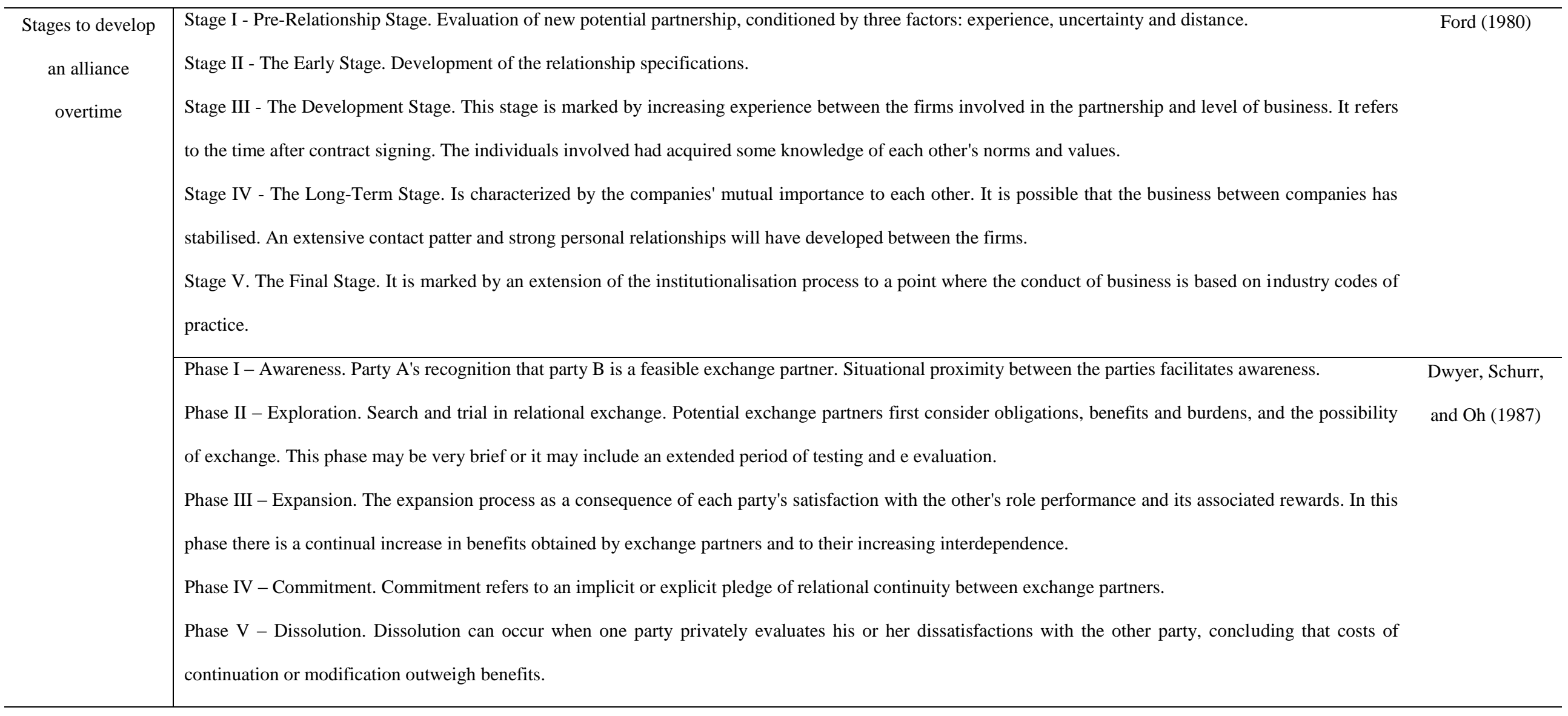




\section{Horizontal Alliances and the Small Retailers}

Horizontal alliances perform a critical role for independents and non-integrated chain retailers in accessing the resources and competencies needed to survive and succeed (Ghisi, Martinelli, and Kristensen, 2006). An effective horizontal alliance can support the fragility which accompanies small retailer firms by providing access and control of a market, supplying competitive information and creating first mover advantages in the identification of market gaps (Frazier and Niehm, 2004). Also, retailers can realise economies of scale and receive assistance in workforce training and development (Litz and Stewart, 2000). This system increases market power of retailers, and leads to higher performance, shared goals, reduced costs, exchange experience; and achieves results that positively impact on competition (Ghisi, Martinelli, and Kristensen, 2006). Horizontal alliance is one of the most important routes to the competitiveness and survival of the small retailers.

During the 1990s, there was growing interest in creating cooperative relations between small and medium sizes companies to improve their competitiveness and enable the supply systems of products (Klint and Sjöberg, 2003). These alliances are particularly valuable to the small business sector, and it is the ideal mechanism for thriving in variable environmental conditions (Donckeks and Lambrecht, 1995).

Although there has been greater interest in recent years by retailers in joint cooperation agreements, retail alliance is not a new phenomenon, as it has existed for many years as predominantly national buying clubs, particularly in France (Robinson and Clarke-Hill, 1995). Horizontal alliances have a long tradition in the retail sector, and cooperative buying 
(for example, within the framework of informal buying groups), constitutes the single most important modality (Zentes and Swoboda, 2000).

In Brazil, strategic horizontal alliances in the retail sector appeared firstly as 'buying groups'. The main focus of retailers in participating in a buying group is the potential to buy cheaper products than when operating alone. Over the years, 'buying groups' were slowly giving way to strategic alliances, extending and diversifying their joint actions. For example, retailers started joint training of employees, studying the market and consumer habits, determining commercial aspects related to the sale of products, sharing transportation expenses, doing marketing campaigns and producing private label jointly (Ghisi, Martinelli, and Kristensen, 2006).

However, despite these optimistic potential advantages, there are some limitations. For horizontal alliances to succeed, it is necessary to have a high level of maturity amongst partners in order to surpass the many barriers of working with competitors. Commitment of the partners is one of the most limiting factors. To assimilate the idea of cooperation and cost-sharing, individual actions have to be substituted by joint actions, which require arduous work (Ghisi, Martinelli, and Kristensen, 2006).

\section{Methodology}

This study began with a deep bibliographic and secondary data research (phase 1). A large amount of material focusing on the theme of 'alliance' was identified; however, little existing literature specifically considered the horizontal alliances between retailers. Because horizontal alliance in retailing has not been studied in depth, an exploratory approach (phase 
2) was conducted with three horizontal retail alliances formed by independent and nonintegrated chain retailers in Brazil; semi-structured, personal interviews with managers of the retail alliances were conducted. The sample was chosen from alliances that act regionally in the state of São Paulo and are know as 'successful cases'.

Further, a qualitative study was conducted with six horizontal retail alliances (phase 3) formed by independents and non-integrated chain retailers among the 10 biggest businesses according to the ranking published by SuperHiper (one of the most representative retail magazines in Brazil). The data was collected through personal interviews. The respondents for this part of the study were retail alliances managers. Considering the resources/funds limitation to conduct this research, just the data of two of the six investigated alliances was collected by personal interviews, as they were located at a distance closer than $300 \mathrm{~km}$. The data of the remaining four alliances were collected by e-mail and telephone (they were located in different states). To analyse the propositions, investigate the correlation among several variables and to describe the characteristics of the alliance in the national territory, a quantitative research was conducted (phase 4) with 21 alliances in several Brazilian states. All of the 150 alliances identified in the country were contacted, but just 21 provided feedback to our innumerous contacts. The resulting data was tabulated and analysed using the SPSS statistic program.

Finally, two qualitative researches were conducted with leaders of the horizontal retail alliances movement in Brazil (phase 5). In both situations, the respondents were owners of retail stores, and active leaders/speakers in conferences about retail alliances in São Paulo state. 
It is relevant to identify that all phases of research were focused on independent and nonintegrated chain retailers; small supermarkets, neighbourhood stores and discount stores that commercialize food products, heath/beauty care products and cleaning products. The owners of these stores mainly concentrate on the demand of the community and they are not economically or physically large. These companies are characterised by stores with less than 400 square metres of floor space and variety and availability of products that is not as vast as that of large retailers.

\section{Findings}

The findings discussed in this article are part of an extensive research program to study retail alliances. Here, the main focus is to explain the theory of alliance in the context of the retail sector in Brazil; particularly to horizontal alliances among small retailers. Due to the vast amount of data collected in several phases; exploratory, qualitative and quantitative researches, several types of information were analysed. For this paper, we selected some specific issues for examination, as explained above; reasons to form a strategic alliance, minimum criteria for the existence of the alliance activity among retailers, steps that managers must take to create a competitive retail alliance, critical core competencies to be developed on the retail alliance, types of retail alliances, forms of strategic retail alliances and stages/steps to develop a retail alliance over time. Other aspects identified in this study are being analysed in parallel; and the results published elsewhere. At the moment, our research team is extending the study to other countries to better understand the 'phenomenon of alliance' and its implications for the retail sector. 
The cases were selected in order to achieve variability and complementarity concerning horizontal alliances. First, the data from each phase of the methodology was analysed separately and then the results were discussed on the basis of consolidated knowledge produced in each phase. The main concern of the study was not to produce statistically valid conclusions and representative set of respondents; the intention was to provide a coherent explanation of the phenomenon alliance in the retail sector. In this sense, the results shown below reflect the summary of the data collected in the personal interviews / questionnaires and the literature studied.

\begin{tabular}{|c|c|}
\hline $\begin{array}{l}\text { Most important } \\
\text { reasons to form a } \\
\text { horizontal alliance } \\
\text { between retailers }\end{array}$ & Potential to purchase cheaper products and the possibility to make joint advertising. \\
\hline $\begin{array}{l}\text { Minimum criteria for } \\
\text { the alliance activity } \\
\text { among retailers exist }\end{array}$ & $\begin{array}{l}\text { 1. Potential benefits; } 2 \text {. Cultural similarity and common characteristics between members; } 3 \text {. } \\
\text { Common vision direction and perspective between members; } 4 \text {. Commitment of partners to joint } \\
\text { future actions and new opportunities; } 5 \text {. Investments in innovation and modernisation. }\end{array}$ \\
\hline $\begin{array}{l}\text { Steps that managers } \\
\text { must take to create a } \\
\text { competitive alliance }\end{array}$ & $\begin{array}{l}\text { 1. Define the purpose of the alliance and scope of the relationship; } 2 \text {. Make a careful examination } \\
\text { of the alliance business plan; } 3 \text {. Choose partners with complementary skills, experience, and that } \\
\text { have similar sized stores; 4. Define dimensions of interaction between members (rights and } \\
\text { obligations); 5. Define actions to reduce the uncertainties of the relationship (partnership will } \\
\text { become easier to manage, facilitating the growth and expansion of the joint actions); 6. Develop a } \\
\text { pilot-project before extending the joint actions to gain knowledge and experience in alliances } \\
\text { activities; } 7 \text {. Focus on long-term results and not on short term benefits; } 8 \text {. Consolidate and } \\
\text { reinforce the best practices between members; } 9 \text {. Establish focus on continuous improvement; } 10 . \\
\text { Development of a balanced scorecard to evaluate continuously the development and performance } \\
\text { of the alliance and promote the required adjustments. }\end{array}$ \\
\hline $\begin{array}{l}\text { Critical core } \\
\text { competencies to be } \\
\text { developed in the retail } \\
\text { alliance }\end{array}$ & $\begin{array}{l}\text { 1. To establish the "philosophy" of the alliance (develop a culture that supports effective } \\
\text { members' collaboration); } 2 \text {. To develop communication skills (facilitating the decisions process, } \\
\text { providing essential feedbacks, and avoiding conflicts that can influence negatively influence } \\
\text { alliance success); } 3 \text {. To develop the ability of retailers to collaborate with each other (a "close }\end{array}$ \\
\hline
\end{tabular}




\begin{tabular}{|c|c|}
\hline & $\begin{array}{l}\text { relationship" focus on commitment); } 4 \text {. To construct a strong and consistent leadership (the leader } \\
\text { emphasises the priorities of the group, engages members in problem solving and their active } \\
\text { cooperation). }\end{array}$ \\
\hline $\begin{array}{l}\text { Types of retail } \\
\text { alliances }\end{array}$ & $\begin{array}{l}\text { We perceived in our study four main types of alliances between retailers: 1. Horizontal retail } \\
\text { alliances formed by independents and non-integrated chain retailers; } 2 \text {. Retail alliances operated } \\
\text { by a wholesaler or retail integrated chain; } 3 \text {. Franchising systems (Vertical marketing systems); } 4 \text {. } \\
\text { Cross-border alliances. }\end{array}$ \\
\hline $\begin{array}{l}\text { Forms of strategic } \\
\text { retail alliances }\end{array}$ & $\begin{array}{l}\text { Joint buying; joint merchandising and promotion; standardisation of stores and uniforms; creation } \\
\text { of joint credit card; joint production of private labels; joint training; joint legal actions; joint } \\
\text { logistics; recruiting and selection of new employees. }\end{array}$ \\
\hline $\begin{array}{l}\text { Stages/steps to develop } \\
\text { an retail alliance over } \\
\text { time }\end{array}$ & $\begin{array}{l}\text { Stage I - Preparation and planning the alliance; Stage II - Starting the alliance; Stage III - } \\
\text { Developing the joint actions; Stage IV - Establishing a long-run relationship. }\end{array}$ \\
\hline
\end{tabular}

\section{Most Important Reasons to Form a Horizontal Alliance between Retailers}

Considering the cases investigated, the most important reason why members join an alliance is the potential to purchase cheaper products (achieve scale) and the possibility to make joint advertising. But as soon as the buying process is consolidated and members gain maturity with the alliance process, new activities are normally incorporated, as a natural event. Two specific situations were noted: some members join an alliance with a limited vision which concerns only survival (operational purpose -short period gains), and others to obtain competitive advantage (strategic purpose -long term perspective); with interest in expanding their actions and, consequently their gains.

\section{Minimum Criteria for Alliance Activity among Retailers}


During the interviews and questionnaire feedbacks, minimum criteria were identified for alliance activity between independent and non-integrated chain retailers. These aspects represent the most common answers cited by respondents:

- Members have to perceive the existence of potential benefits: Otherwise they would not be interested in becoming a member of a horizontal alliance. Considering the pros and cons, is it advantageous to join the alliance? They should ask themselves an objective question: Do the potential benefits justify this course of action?

- Cultural similarity and common characteristics between members: The horizontal alliance consists of a set of relationships between members who interact socially to exchange and share resources and capabilities. It is a complex relationship that requires retailers to share ideas and ideals. In this sense, cultural differences may directly influence communication between members, the need of the alliance coordination, and the business transactions. On the other hand, the presence of cultural similarities between retailers means that they share philosophy and ideas (the "cultural fit"), and this can facilitate cooperation based on a common direction of the work-force; helping to reduce the difficulty in conflict resolution. Some respondents also emphasised that cultural similarities can be facilitated by chosen partners with similar characteristics, especially considering the aspect of 'size'. They believe that alliances formed by members that own similar sized stores and have similar financial, human, and technological structure, are more likely to succeed. It is likely that they have similar capabilities and resources, and deal with similar problems and needs.

- Common vision, direction and perspective between members: What are the expectations of partners in the alliance? It is essential that retailers define a precise purpose, a common vision on priorities to be achieved, and move in a consistent direction. This implies that from the beginning of the alliance formation it is necessary to create a common and 
realistic sense of expectation and understanding among all participants; facilitating the coordination of their movements and avoiding frustration.

- Commitment of partners to joint future actions and opportunities: It is not in all situations that members are prepared to make long-term commitments. Commitment is one of the most critical aspects to be developed to create a permanent alliance. A strong integration and commitment, and that includes loyalty, trust, fidelity and a sense of duty is necessary to promote the sense of togetherness and to ensure the group's long-term growth. When members are enjoined in the mission, the actions resulting from the collaboration can be easier sustained. Lack of commitment was pointed out as a critical aspect in the alliance's sustainability by many respondents from alliances in initial and mature phases.

- Investments in innovation and modernisation: To be part of a horizontal alliance means that retailers are trying to improve their effectiveness and business gains. In many situations, it will be required (from retailers' resources) to make investments to improve the necessary conditions and infrastructure in order to achieve the alliance's goals. Training employees, making adjustments in technology/ system and improving management methods and transportation infrastructure were areas pointed out by respondents as requiring new investments.

\section{Steps that Managers Must Take to Create a Competitive alliance}

Managers will have to concentrate their attention in some steps to create a competitive alliance, and must:

- Define the purpose of the alliance and scope of the relationship: Without a clear purpose and realistic objectives, the alliance progress has no direction, decisions are made inconsistently; and the desired outcomes will be difficult to reach. Defining the purpose of 
the alliance will give retailers a direction, facilitating the definition of a consistent set of policies to follow. For members to understand their role and be committed, it is also necessary to have a clear definition of the relationship specifications. The most common aspects cited by respondents in this sense were the limits and duration of the relationship. When the purpose of the alliance and scope of the relationship are clear, members know exactly what to expect from the union.

- Make a careful examination of the alliance business plan: The definition of a workable plan is necessary to produce fundamental decisions and actions on the alliance's future. Which direction should the alliance take? Defining a plan direction requires the construction of strategies to produce fundamental decisions and actions on the alliance future. This plan can guide retailers to focus their energy at the same goals to improve the current conditions and achieve the desired future. Without a plan direction, the alliance will not sustain in the long run. This plan has to be discussed and defined with the participation of all retailers' members in order to facilitate their commitment in the whole process. It is important to establish the main aspects involved concerning: financial nature, necessity of investments, limitations of costs and stated periods of execution.

- Choose partners with complementary skills, experience, and that have similar size stores: In order to reduce conflict related to expectations about the future of the alliance, respondents cited the need of choosing partners with similar size stores (that probably have similar resources) and have complementary skills; and are able to exchange experience and knowledge.

- Defining the dimensions of interaction between members: What are the obligations and rights of members? What behaviour and posture are expected from them? What are the consequences of the violation of these statements? In most situations rights and obligations are components established by statutes and regulations and contracts when the 
horizontal alliance is formalised. Defining a consistent set of rules can facilitate members discipline and procedures that are necessary to conduct the alliance. We noticed that some of these dimensions were based on a formal contract; in other situations, they were based on ethical values. However, it was very clear in the research that retailers believe (independently of a contract or not) that the definition of rights and obligations can reduce conflict in the alliance.

- Define actions to reduce the uncertainties of the relationship (partnership will become easier to manage, facilitating the growth and expansion of the joint actions): Even considering this aspect which is complex and not easy to be administrated, respondents pointed out the need to reduce the uncertainties of the relationship in order to consolidate the alliance in the long term. The question in this sense is: what are the steps needed to reduce uncertainties associated with the relationship? Respondents identified some issues that have to be handled: individualistic attitudes (opportunists actions), lack of members' commitment, resistance in sharing information, delays in the payment of suppliers, insolvency of retailer members, communication problems, lack of professionalism actions, and reluctance in making changes.

- Develop a pilot-project before extending the joint actions, in order to gain knowledge and experience in alliances activities: It is an opportunity to test, evaluate, and learn and to make the necessary adjustments. For example, they can adopt a pilot project focusing on buying a limited line of products together. The adoption of a pilot can be especially useful when there are doubts about the positive and negative aspects resulting from alliance activities.

- Focus on long-term results and not on short term benefits: In many horizontal alliances short-term benefits dominate the behaviour of retailers, because they want to reap the rewards "as soon as possible". Members have to realise that some improvements and gains 
can be achieved in a short period of time, but some others will occur slowly, over time, as a result of the solid progress of alliance.

- Consolidate and reinforce the best practices between members: This is not different from other organisations; an alliance needs to identify the 'best procedures' for each activity for ensuring standards. It is important that retailers prioritise the best practices, communicate, and reinforce them to all members.

- Establish a focus on continuous improvement (insert new activities, modernise process and technologies): When retailers became a part of an alliance, they probably will have to spend some money to update and improve their internal capability. But not only in the beginning of the alliance formation, as the dynamic of the retail market requires constant new adaptations. Continuous improvement is required in order to remove activities that have no value, and to optimise quality and performance and improve efficiency.

- Development of a balanced scorecard to continuously evaluate the development and performance of the alliance and promote the required adjustments: To make the necessary improvements to construct a solid and successful horizontal alliance, it is necessary to continuously review alliance performance. By adopting quantitative and qualitative metrics, retailers can evaluate alliance progress, identify gaps, and make the necessary changes to improve performance. But of course, retailers have to be prepared and predisposed to make adjustments; otherwise, this evaluation is a waste of time. The questions that should be answered by retailers are: Are we doing the right thing and in the right way? What changes are required to improve the alliance performance? Which resources (financial, human, infrastructure) and efforts are required in this process of change? Although the continuous revision of alliance performance was identified as an essential step in many investigated cases, the adoption of indicators was not identified. 


\section{Critical Core Competencies to be Developed in the Retail Alliance}

Core competencies can be understood to be the fundamental knowledge and skills, and the required behaviours that are essential to guarantee competitive advantage to the alliance. Core competences are not easy to be duplicated by competitors because they are specific to each individual organisation. In the horizontal alliance, they represent the basic attributes and critical abilities needed by all retailers' members to provide effective competitiveness. The main question that all retailers should discuss to develop their core competences is: What are the fundamental behaviours, skills and knowledge that should be delineated to construct an effective alliance? In defining core competencies, retailers can better formulate strategies to objectively guide their future actions.

The most critical core competences cited by respondents refer to the 'idea', the 'philosophy' of the alliance. This means they have a competitive advantage because they developed a culture that supports the effective members' collaboration; a new culture of sharing commitment, and learning together. When retailers understand the various roles of the alliance, its principles, mission, structure and operations, it become easier to articulate collective knowledge, share information, and promote effective communication. To develop these aspects, retailers have to substitute traditional acts for cooperative behaviour. The culture of the alliance has an enormous impact on retailers' habits and behaviour, affecting the whole alliance performance. This means that a strong culture can better support the stability of the relationship, serving as a guide for required behaviours. In this sense, a strong culture should include elements to develop a sense of belonging and encourage the development of shared beliefs and the networking process. However, it is not simple to create this new culture. Each alliance has to 
develop its own philosophy. Many respondents pointed out that 'their culture makes the difference', promoting an atmosphere conducive to developing the alliance's activities.

The second aspect identified refers to the need to develop communication skills. In an alliance, the coordination of the communication between members is more complex than in a singular firm, because it involves members with different cultures and expectations. Providing an efficient and solid inter-firm communication, with the purpose of exchanging ideas and information can facilitate the decision-making process, provide essential feedback and avoid conflicts that can negatively influence the alliance's success. The manager of the alliance is responsible for developing an effective communication channel, so it is important that he creates specific relationships and environments that invite members' participation. In many cases respondents cited the need of regular meetings with all retailers to discuss important issues.

Another important aspect identified refers to the ability of retailers to collaborate with each other. When retailers decide to join an alliance, they should be prepared to be part of a team, which means that they should embrace new ideas, new approaches, and a 'new cause'. To develop a 'close relationship' focused on commitment can be an important differential. Collaborative work in an alliance requires cooperation, shared responsibility, proactive behaviour, a sense of mutuality and a high level of involvement and commitment of retailers. It is important to clarify to retailers what they can expect to gain from this membership and how they are to manage the collaborative processes to achieve common goals. In many cases investigated we found existence of informal meetings used to promote interaction and team building amongst group members. 
Finally, we detected that some alliances have a differential because they constructed a strong and consistent leadership that helps members to create a future vision and define action plans. In a horizontal alliance it is common that a retailer member assumes the leadership of the group, occupying a key position in the structure of the alliance. In many cases investigated, retailers' leaders were stimulating partnership-building, developing actions to support the alliance's mission, and dealing with suppliers in order to defend the interests of the group. Some respondents emphasised that when a strong leadership does not exist, the involvement and participation of members can be reduced. In this sense, it is clear that the leader assumes an important role in the alliance's success, because he/she is the one who emphasises the priorities of the group, and engages members in problem solving and their active cooperation.

\section{Types of Retail Alliances}

In reviewing the literature identified were four most common types of alliance among retailers:

- Horizontal retail alliances formed by independents and non-integrated chain retailers: Composed mainly of small and medium retailers (neighborhood stores), in many cases family-owned retailers, with limited resources that decided to group together with other retailers to create economies of scale; to improve their competitiveness, to strengthen their market position and voice in the industry by leveraging the collective knowledge and experience. These alliances are denominated 'horizontal' because it is formed between members at the same level in the distribution chain.

- Retail voluntary alliances operated by a wholesaler or a retail integrated chain: Based in a vertical marketing system arrangement (independent firms at different levels in the distribution chain), this alliance is characterised by a wholesale (or in some cases, retailer) 
commanding (sponsoring) organisation and provides services for a group of retailers (retailers of different sizes and structures); including a broad range of products and services. The wholesaler/ retailer provides assistance to affiliated members, permitting them to achieve buying economies, to increase their sales and profits and improve their operational efficiency.

- Franchising systems (vertical marketing systems): Vertical alliance collaboration, based on the system-forming rules of franchising, which is focused on commitments and obligations of the respective membership. The retailers (franchisees of different sizes and structures) have the advantage of the experience and the reputation of the franchisor to assist in improving performance and competitiveness. The franchisor acts as a manufacturer or wholesaler (they allow exclusivity to commercially use the rights of third parties), giving their membership a brand-name, or at least a logo; and a complete package business model (standard quality and uniformity of products and services) that represents the exact reproduction of a successful business.

- Cross-border alliances: This horizontal alliance involves large retail organisations on a supranational level, displaying various degrees of collaboration, with the intention of expanding their markets and distribution channels; and creating economies of scale in products and processes. The group acts as a single purchasing unit, as well as often collaborating on the sourcing of private label products. Together they can upgrade their capabilities and compete more efficiently in global markets.

\section{Forms of Strategic Retail Alliances}

In our quantitative research (methodology - step 4, with 21 cases) we noted that retailers develop the following collective actions: joint product buying (21 cases); joint merchandise 
and promotion (20 cases); standardisation of stores and uniforms (12 cases); creation of joint credit card (11 cases); joint production of private labels (10 cases); joint training (10 cases); joint legal actions (7 cases); joint logistics (7 cases) and recruiting and selection of new employees ( 2 cases).

\section{Stages and Steps to Develop a Consolidated Horizontal Retail Alliance over Time}

Based on the answers of the respondents and the literature investigated, we define steps that retailers have to take to construct a horizontal alliance over time:

- Stage 1 - Preparation and planning the alliance. The effort in this first stage is to define the focus and characteristics of the alliance, and its planning. It is important to understand the reasons for forming the association, what its focus is, who the members involved will be and what their expectations are. It is necessary to clarify what the advantages of being a member of the alliance are and what efforts and costs are required (capital structure, human and information). It is important to choose partners with complementary skills and experience, and then develop the ability of retailers to collaborate with each other. In this stage the alliance is being formed, so attention has to be given to create a culture that supports effective members' collaboration and commitment. When retailers understand the various roles of the alliance, its principles, mission, structure and operations, it becomes easier to articulate collective knowledge, share information, and promote effective communication. The steps that should be taken in this stage are to: (1) Analyse the advantage of being part of a strategic alliance; (2) Identify the need of resources (capital structure, human, information) to maintain and operate the alliance; (3) Define clearly the objectives and propose of the alliance; (4) Define the agreement aspects: contractual or non-contractual relationship; (5) Construct the alliance (election of the board); (6) Define 
the dimensions of interaction between members (rights and obligations); (7) Formalise the alliance: constitution of the alliance statute (establishment of the institution - legal and specific regulation dispositions); (8) Define the action plan of the alliance: planning the future actions; (9) Establish the communication channels to support an effective communication.

- Stage II - Starting the alliance. In this stage, the main focus is on the internal processes (infrastructure, procedures, equipments, etc.) to support the joint activities between members. Retailers should start this collaborative action through the development of a pilot project in order to test, evaluate, and learn. In this stage it is essential to check the actual performance of the organisations involved and the standards required in adjusting the internal processes to facilitate the operations and joint actions. It is necessary to adapt the internal processes and infrastructure, and technology and human resources (internal optimisation). As the union and actions among actors become more complex, it is fundamental to define actions to reduce uncertainties of the relationship, to facilitate the expansion process. Retailers must define quality standards (best procedures) and prioritise the best practices, communicating and reinforcing them to all members. The steps that should be taken in this stage are to: (1) Apply the internal capacity (internal optimisation), facilitating operations and joint actions; (2) Develop joint actions, starting with a projectpilot; (3) Define actions to reduce the uncertainties of the relationship - partnership will become easier to manage, facilitating the growth and expansion of the joint actions; (4) Consolidate and reinforce best practices - define quality standards for implementation and dissemination between members; (5) Develop a balanced scorecard to evaluate the development and performance of the alliance and promote the required adjustments. 
- Stage III - Developing the joint actions. This stage is characterised by the strength of the members' relationship and by the growth and strength of joint actions. It is fundamental to create synergies between partners to support new joint actions and to reduce the instability of the relationship; and this helps to create trust. The following steps should be taken at this stage: (1) Reinforce the collaborative working environment to create an atmosphere of trust and reciprocity; (2) Consolidate and amplify the focus on joint actions, and introduce new joint activities; (3) Create mechanisms to reduce the cultural actions between members; (4) Make the decisions about the alliance dimension and expansion; (5) Evaluate the performance of the alliance (balanced scorecard) and promote the required adjustments.

- Stage IV - Establishing a long-run relationship. This stage is characterised by the high level of experience of the retailers involved, by the establishment of trust, norms, and processes standardisation. At this point, retailers need to expand premises and put more energy in place if they want to keep growing. It is important for retailers to diversify their services and act proactively to develop new opportunities. To be part of a horizontal alliance means that retailers are trying to improve their effectiveness and gains. In many situations, it will require investments to improve the necessary conditions and infrastructure to achieve the alliance's goals. Retailers must establish a focus in a continuous improvement, inserting new activities, and modernising process and technologies. In this stage the steps that should be taken are to: (1) Identify the differential aspects to reinforce the alliance competitiveness; (2) Establish partnerships with suppliers; (3) Consolidate a strong, real and consistent relationship with consumers, providing them with new services; (4) Develop continuously the technological and structural integration 
and modernisation of processes and actions; (5) Evaluate the performance of the alliance (balanced scorecard) and promote the required adjustments.

\section{Conclusions and Recommendations}

This study investigated horizontal alliance among independent and non-integrated chain retailers. It discussed the reasons for forming a horizontal alliance; the minimum criteria for alliance activity; the steps that managers must take to create a competitive alliance; the critical core competencies to be developed; the types of retail alliances; and the stages / steps to develop workable horizontal retail alliance over time.

Considering the most important reasons to form a horizontal alliance, it is concluded that:

- Retailers form the alliance to buy cheaper products. They are more focused on 'survival than gaining competitive advantage' (Murray and Mahon, 1993). This happens because many retailers decide to join an alliance when the conditions to maintain their business do not seem optimistic.

- 'Reciprocity' is present in the retailers' cooperation, as this collaborative effort has been adopted to obtain mutually beneficial goals (Oliver, 1990).

- The reasons for forming horizontal alliance do also reflect an 'operational purpose', as retailers are interested in growth opportunities (Clarke-Hill, Robinson, and Bailey, 1998).

- Horizontal alliances reflect a 'market-related reason', as retailers intend to reduce costs and gain access to new suppliers (Vyas, Shelburn, and Rogers, 1995).

Referring to the minimum criteria for the existence of alliance activity, identified are some aspects that extend previous findings (Murray and Mahon, 1993). Without the existence of 
potential benefits, cultural similarities, and characteristics between retailers, common vision direction, commitment, and investments in innovation and modernisation, the horizontal alliance will probably not succeed; as these factors are critical in the process of its formation and development. These aspects were set out by most respondents as essential and minimum requirements to construct a horizontal alliance.

Other issues analysed refer to the steps that managers must take to create a competitive alliance. Based on the empirical research, some other aspects that can complement Pekar and Allio (1994) were found, including the definition of rights and obligations and the consolidation and reinforcement of best practices. Managers have to coordinate the whole activities involved between the definition of the alliance purpose and the evaluation of its performance.

Reported are four main core competencies that can make a difference to a horizontal alliance achieve competitive advantage. The aspects of 'the idea' (to create a vision in which partners play a critical role) and 'the climate' (to create an atmosphere of trust and reciprocity), which have previously been discussed in the literature (Lorenzoni and Baden-Fuller, 1995), have some similarities with the results found. The first core competence discussed refers to the development of the alliance 'philosophy'. This means retailers will have to develop a culture that supports effective members' collaboration. This aspect also can be understood as the creation of a vision for the alliance and its importance (cf. Lorenzoni and Baden-Fuller, 1995). Regarding 'the climate', it was clear from the study that when retailers decide to join an alliance, they should be prepared to be part of a team; focused on commitment; and interaction should be conducted in an atmosphere of trust and reciprocity. The other two core competencies identified refer to the development of communication skills and the 
construction of a strong and consistent leadership. In an alliance, the coordination of communication between members is more complex than in a singular firm, because it involves members with different cultures and expectations. In this sense, to develop communications skills can facilitate whole group coordination. It was also detected that some alliances have a differential because they constructed a strong and consistent leadership that helps members to create a future vision and define action plans.

Identified are four main types of alliances between retailers: horizontal retail alliances formed by independents and non-integrated chain retailers; retail voluntary alliances operated by a wholesaler or retail integrated chain; franchising systems (vertical marketing systems); and cross-border alliances. The first type is typically a 'Y-alliance': retailers form an alliance with other retailers to compensate for structural competitive disadvantages in relation to chain store companies; and have local or national scope (Zentes and Swoboda, 2000). In Brazil, this type of alliance is formed by independent and non-integrated chain retailers localised in the same state or in nearby states, which means they are local or regional alliances. The retail voluntary alliances operated by a wholesaler or retail integrated chain, and the franchising systems alliances can be characterised as 'Y-alliances'; if their orientation is local / national, or 'X-alliances', if they are cross-border extension, consolidated on a supranational level. For example, some franchising groups can expand their extension to other countries ('Xalliances'). Finally, the last type described - cross-border alliances - are typically ' $\mathrm{X}$ alliances'. They are particularly very common in European countries, formed by global retailers, with high profits and bargaining power.

The study also identifies the forms of strategic alliances. Considering the ones cited by Elmuti and Kathawala (2001), the horizontal alliances investigated were developing joint 
merchandise and promotion, joint production of private labels, and joint logistics. Most were focused especially in buying actions.

Finally, discussed are the stages and steps to develop a consolidated alliance over time. In stage I ('Preparation and planning the alliance') effort should be in defining the focus, characteristics of the alliance, and its planning. Nine essential steps were described to reach this purpose. In stage II ('Starting the alliance') the alliance is created and the focus should be on joint action development and internal process adequacy (infra-structure, procedures, equipment, etc.) to support activities between members. Five steps were defined, including, for example, the adoption of a pilot project. In stage III ('Developing the joint action'), the attention is on the strength of the members' relationship and on the growth and strength of joint action. Five basic steps were pointed out, starting with reinforcing of the collaborative working environment and concluding with the evaluation of alliance performance. In stage IV ('Establishing a long-run relationship'), retailers need to expand premises and put more energy in place if they want to keep growing. Five steps were identified, concentrating on the development of new services and opportunities.

The proposal of stages and steps provided in this paper integrate the results of the empirical research and the literature investigated. The three steps discussed by Lei, Slocum, and Pitts (1997) - "partner selection, planning and implementation/control"- were also identified by respondents as critical steps to consolidate the alliance evolution. However, even if the study showed that very few horizontal alliances investigated had adopted performance measurements to improve competitiveness, we considered this an essential element, and it was included in our proposal. Ford (1980) also provides some relevant insights about the development of the 'relationship specifications'; and Hoffmann and Schosser (2001) had an 
important contribution in defining the 'management of the partnership'. These aspects were incorporated in our recommendations. Some arguments treated in the work of Dwyer, Schurr, and Oh (1987), specifically in consideration of the 'exploration phase' and 'expansion', complement some of the ideas cited by respondents, and were also included in our discussion.

Discussed also were fundamental aspects of the alliance paradigm in the context of the horizontal retail alliances. This explanation provides some new insights to both academics and practitioners to better understand and respond to the challenges involved in the formation and consolidation of horizontal retail alliances. However, the results of this study make clear the need of new theoretical and empirical researches with a view to deepening the understanding of retail alliances. Additional contribution should come from analysing the different types of retail alliances and a comparison between horizontal and vertical alliances in retailing. Further studies could also bring some relevant contribution through understanding different issues that influence the competitiveness of retail alliances.

This paper expands on the existing literature of horizontal alliances in the retail sector; however, this study was conducted in Brazil, a country with an environment probably significantly different from those in developed countries and in other developing ones. In this sense, we encourage further research in other countries with contrasting cultures to add a broad comprehension and perspective of the horizontal alliances phenomenon. The study of the theme must be continued, given its importance for the effectiveness and survival of independent and non-integrated chain retailers.

\section{References}


Bailey, J., Clarke-Hill, C.M., and Robinson, T.M. (1995), "Towards a taxonomy of international retail alliances", Service Industries Journal, Vol. 15, No. 4, pp. 25-41.

Barnir, A. and Smith, K.A. (2002), "Interfirm alliances in the small business: the role of social networks", Journal of Small Business Management, Vol. 40, No. 3, pp. 219-233.

Baron, S., Harris, K., Leaver, D., and Oldfield, B.M. (2001), "Beyond convenience: the future for independent food and grocery retailers in the UK", International Review of Retail, Distribution, and Consumer Research, Vol. 11, No. 4, pp. 395-414.

Bengtsson, M. and Kock, S. (1999), "Cooperation and competition in relationships between competitors in business networks", Journal of Business and Industrial Marketing, Vol. 14, No. 3, pp. 178-193.

Byrom, J., Medway, D., and Warnaby, G. (2003), "Strategic alternatives for small retail business in rural areas", Management Research News, Vol. 26, No. 7, pp.33-49.

Chung, Q.B, Luo, W., and Wagner, W.P. (2006), "Strategic alliance of small firms in knowledge industries: a management consulting perspective", Business Process Management Journal, Vol. 12, No. 2, pp. 206-234.

Clarke-Hill, C.M, Robinson, T.M., and Bailey, J. (1998), "Skills and competence transfers in European retail alliances: a comparison between alliances and joint ventures", European Business Review, Vol. 8, No. 6, pp. 300-310.

Coca-Stefaniak, A., Gallsworth, A.G., Parker, C., Bainbridge, R., and Yuste, R. (2005), "Decline in the British small shop independent retail sector: exploring European parallels", Journal of Retailing and Consumer Services, Vol. 12, No. 5, pp. 357-371.

D'Andrea, G., Lopez-Aleman, B., and Stengel, A. (2006), "Why small retailers endure in Latin America", International Journal of Retail \& Distribution Management, Vol. 34, No. 9, pp. 661-673. 
Dawson, J.A. and Kirby, D.A. (1979), Small scale retailing in the UK, Saxon House, Farnborough.

Dobson, P.W. (2002), "Retailer buyer power in European markets: lessons from grocery supply", Research Series, No. 2002:2, Business School, Loughborough University.

Donckels, R. and Lambrecht, J. (1995), "Network and small business growth: an explanatory model", Small Business Economics, Vol. 7, No. 4, pp. 273-289.

Doz, Y.L. (1996), "The evolution of cooperation in strategic alliances: initial conditions or learning processes?" Strategic Management Journal, Vol. 17, special issue, pp. 55-83.

Dwyer, F.R., Schurr, P.H., and Oh, S. (1987), "Developing buyer-seller relationships", Journal of Marketing, Vol. 51, No. 2, pp. 11-27.

Elg, U. and Johansson, U. (1996), "Networking when national boundaries dissolve", European Journal of Marketing, Vol. 30, No. 2, pp. 61-74.

Elmuti, D. and Kathawala, Y. (2001), "An overview of strategic alliances", Management Decision, Vol. 39, No. 3, pp. 205-217.

Ensign, P.C. (1998). Interrelationships and horizontal strategy to achieve synergy and competitive advantage in the diversified firm. Management Decision, v. 36, iss. 10, pp.657-668.

Farina, E.M.M.Q., Nunes, R., and Monteiro, G.F. (2005), "Supermarkets and their impacts on the agrifood system of Brazil: the competition among retailers", Agribusiness, Vol. 21, No. 2, pp. 133-147.

Ford, D. (1980), "Buyer/seller relationship in international industrial markets", European Journal of Marketing, Vol. 14, No. 5/6, pp. 101-112.

Frazier, B. and Niehm, L.S. (2004), "Exploring business information networks of small retailers in rural communities", Journal of Developmental Entrepreneurship, Vol. 9, No. 1, pp. 23-42. 
Ghisi, F.A., Martinelli, D.P., and Kristensen, T. (2006), "Horizontal cooperation among small and medium-sized supermarkets as a tool for strengthening competitiveness", in Bijman, J., Omta, S.W.F., Trienekens, J.H., Wijnands, J.H.M., and Wubben, E.F.M. (Eds.), International Agri-food Chains and Networks: Management and organization, Wageningen Academic Publishers, Wageningen, pp.113-132.

Hipkin, I. and Naudé, P. (2006), "Developing effective alliance partnerships: lessons from a case study", Long Range Planning, Vol. 39, No. 1, pp. 51-69.

Hoffman, W.H (2005), "How to manage a portfolio of alliances", Long Range Planning, Vol. 38, No. 2, pp. 121-143.

Hoffman, W.H. and Schlosser, R. (2001), "Success factors of strategic alliances in small and medium-sized enterprises: an empirical survey", Long Range Planning, Vol. 34, No. 3, pp. $357-381$.

Jarratt, D.G. (1998), "A strategic classification of business alliances: a qualitative perspective built from a study of small and medium-sized enterprises", Qualitative Market, Vol. 1, No. 1, pp. 39-49.

Kauser, S. and Shaw, V. (2004), "International strategic alliances: objectives, motives and success", Journal of Global Marketing, Vol. 17, No. 2/3, pp. 7-43.

Klint, M.B. and Sjöberg, U. (2003), "Towards a comprehensive SCP-model for analyzing strategic networks/alliances", International Journal of Physical Distribution \& Logistics Management, Vol. 33, No. 5, pp. 408-426.

Kumar, R. and Nti, K.O. (2004), "National cultural values and the evolution of process and outcome discrepancies in international strategic alliances", Journal of Applied Behavioral Science, Vol. 40, No. 3, pp. 344-361.

Lei, D. (1993), "Offensive and defensive uses of alliances", Long Range Planning, Vol. 26, No. 4, pp. 32-41. 
Lei, D., Slocum, J.W., and Pitts, R.A. (1997), "Building cooperative advantage: managing strategic alliances to promote organizational learning", Journal of World Business, Vol. 32, No. 3, pp. 203-223.

Litz, R.A. and Stewart, A.C. (2000), "Trade name franchise membership as a human resource management strategy: does buying group training deliver 'true value' for small retailers?" Entrepreneurship Theory and Practice, Vol. 25, No. 1, pp. 125-136.

Lorenzoni, G. and Baden-Fuller, C. (1995), "Creating a strategic center to manage a web of partners", California Management Review, Vol. 37, No. 3, pp. 146-163.

Masurel, E. and Janszen, R.A. (1998), "The relationship between SME cooperation and market concentration: evidence from small retailers in the Netherlands", Journal of Small Business Management, Vol. 36, No. 2, pp. 68-73.

McGee, J.E. and Rubach, M.J. (1996/1997), "Responding to increased environmental hostility: a study of the competitive behavior of small retailers", Journal of Applied Business Research, Vol. 13, No. 1, pp. 83-95.

Megicks, P. (2001), "Competitive strategy types in the UK independent retail sector", Journal of Strategic Marketing, Vol. 9, No. 4, pp. 315-328.

Murray, E.A. and Mahon, J.F. (1993), "Strategic Alliances: gateway to the new Europe?" Long Range Planning, Vol. 26, No. 4, pp. 102-111.

O'Donnell, A., Gilmore, A., Cummins, D., and Carson, D. (2001), "The network construct in entrepreneurship research: a review and critique", Management Decision, Vol. 39, No. 9, pp. 749-760.

Oliver, C. (1990), "Determinants of interorganizational relationships: integration and future directions", Academy of Management Review, Vol. 15, No. 2, pp. 241-265.

Pekar, P. and Allio, R. (1994), "Making alliances work: guidelines for success", Long 
Reijnders, W.J.M. and Verhallen, T.M.M. (1996), "Strategic alliances among small retailing firms: empirical evidence for the Netherlands", Journal of Small Business Management, Vol. 34, No. 1, pp. 36-46.

Rindfleisch, A. (2000), "Organizational trust and interfirm cooperation: an examination of horizontal versus vertical alliances", Marketing Letters, Vol. 11, No. 1, pp. 81-95.

Rings, P.S. and Van de ven, A.H. (1994), "Developmental processes of cooperative interorganizational relationships", Academic of Management Review, Vol. 19, No. 1, pp. 90-118.

Robinson, T. and Clarke-Hill, C.M. (1995), "International alliances in European retailing", The International Review of Retail, Distribution and Consumer Research, Vol. 5, No. 2, pp. $167-184$.

Shaw, S.A., Dawson, J.A., and Harris, N. (1994), "The characteristics and functions of retail buying groups in the United Kingdom: results of a survey", International Review of Retail, Distribution \& Consumer Research, Vol. 4, No. 1, pp. 83-105.

Sheth; J.A. and Parvatiyar, A. (1992), "Towards a theory of business alliance formation", Scandinavian International Business Review, Vol. 1, No. 3, pp. 71-87.

Smith, A. and Sparks, L. (2000), "The role and function of the independent small shop: the situation in Scotland", International Review of Retail, Distribution, and Consumer Research, Vol. 10, No. 2, pp. 205-226.

Spekman, R.E, Forbes, T.M.; Isabella, L.A.; Macavoy, T.C. (1998), "Management: a view from the past and a look to the future", Journal of Management Studies, Vol. 35, No. 6, pp. $747-772$.

Stoel, L. (2002), "Retail cooperatives: group size, group identification, communication frequency and relationship effectiveness", International Journal of Retail \& Distribution Management, Vol. 30, No. 1, pp. 51-60. 
Vyas, N.M., Shelburn, W.L., and Rogers, D.C. (1995), "An analysis of strategic alliances: forms, functions and framework", Journal of Business \& Industrial Marketing, Vol. 10, No. 3, pp. 47-60.

Wingate, J.W. (1941), "Current trends in retail distribution", Journal of Marketing, Vol. 5, No. 4, pp. 410-422.

Zentes, J. and Swoboda, B. (2000), "Allied groups on the road to complex networks", Technology Society, Vol. 22, pp. 133-150. 